Article

\title{
A Two-Dimensional Numerical Study of Hydrodynamic, Heat and Mass Transfer and Stability in a Salt Gradient Solar Pond
}

\section{Ridha Boudhiaf *, Ali Ben Moussa and Mounir Baccar}

Unit of Computational Fluid Dynamics and Transfer Phenomena (CFDTP), Department of Mechanical Engineers, National Engineering School of Sfax, Street of Soukra, Km 3.5, B.P. 1173, Sfax 3038, Tunisia; E-Mails: ali.benmoussa@ipeis.rnu.tn (A.B.M.); mounir.baccar@enis.rnu.tn (M.B.)

* Author to whom correspondence should be addressed; E-Mail: ridhaboudhiaf@yahoo.fr; Tel.: +216-74-274-409/418 (ext. 395); Fax: +216-74-275-595.

Received: 24 May 2012; in revised form: 25 September 2012 / Accepted: 8 October 2012 / Published: 18 October 2012

\begin{abstract}
In this work, the problem of hydrodynamic, heat and mass transfer and stability in a salt gradient solar pond has been numerically studied by means of computational fluid dynamics in transient regime. The body of the simulated pond is an enclosure of height $\mathrm{H}$ and length L wherein an artificial salinity gradient is created in order to suppress convective motions induced by solar radiation absorption and to stabilize the solar pond during the period of operation. Here we show the distribution of velocity, temperature and salt concentration fields during energy collection and storage in a solar pond filled with water and constituted by three different salinity zones. The bottom of the pond is blackened and the free-surface is subjected to heat losses by convection, evaporation and radiation while the vertical walls are adiabatic and impermeable. The governing equations of continuity, momentum, thermal energy and mass transfer are discretized by finite-volume method in transient regime. Velocity vector fields show the presence of thin convective cells in the upper convective zone (UCZ) and large convective cells in the lower convective zone (LCZ). This study shows the importance of buoyancy ratio in the decrease of temperature in the UCZ and in the preservation of high temperature in the LCZ. It shows also the importance of the thickness of Non-Convective Zone (NCZ) in the reduction of the upwards heat losses.
\end{abstract}

Keywords: energy collection and storage; transient fluid flow, heat and mass transfer; salt gradient solar pond; solar radiation absorption; computational study 


\section{Nomenclature}

A

$\mathrm{C}$

$\Delta \mathrm{C}$

$\mathrm{C}_{\mathrm{pa}}$

$\mathrm{C}_{\mathrm{p}}$

D

E

g

$\mathrm{H}$

$\mathrm{h}_{\mathrm{c}}$

L

LCZ

$\mathrm{L}_{\mathrm{v}}$

Le

$\mathrm{N}$

$\mathrm{NCZ}$

$\mathrm{p}$

$P$

Pr

$\mathrm{P}_{\mathrm{S}}$

$P_{v}$

$\mathrm{P}_{\mathrm{atm}}$

$\mathrm{q}_{\mathrm{c}}$

$\mathrm{q}_{\mathrm{e}}$

$\mathrm{q}_{\mathrm{r}}$

$\mathrm{q}_{\mathrm{t}}$

$\mathrm{q}_{\mathrm{i}}$

$\mathrm{q}_{0}$

$\mathrm{q}(\mathrm{z})$

$\mathrm{Ra}_{\mathrm{T}}$

$\mathrm{Ra}_{\mathrm{I}}$

$\mathrm{R}_{\mathrm{h}}$

$\mathrm{Ra}_{\mathrm{S}}$

Sc

$\mathrm{t}$

$\Delta \mathrm{T}$

$\mathrm{T}$

$\mathrm{T}_{\mathrm{s}}$

$\mathrm{T}_{\mathrm{a}}$ aspect ratio.

$\left(\mathrm{A}=\mathrm{LH}^{-1}\right)$

concentration of solution.

$\left(\mathrm{kg} \mathrm{m}^{-3}\right)$

concentration difference.

$\Delta \mathrm{C}=\mathrm{C}_{\max }-\mathrm{C}_{\min }$

specific heat of air....

.$\left(\mathrm{kJ} \mathrm{kg}^{-1}{ }^{\circ} \mathrm{C}^{-1}\right)$

specific heat of solution.

.$\left(\mathrm{kJ} \mathrm{kg}^{-1}{ }^{\circ} \mathrm{C}^{-1}\right)$

diffusion coefficient.

$\left(\mathrm{m}^{2} \mathrm{~s}^{-1}\right)$

dimensionless thickness

acceleration due to gravity.

$\left(\mathrm{m} \mathrm{s}^{-2}\right)$

height of the solar pond.

convective heat transfer coefficient

$\left(\mathrm{Wm}^{-2}{ }^{\circ} \mathrm{C}^{-1}\right)$

length of the solar pond.

lower convective zone

latent heat of water evaporation

$\left(\mathrm{J} \mathrm{kg}^{-1}\right)$

Lewis number

buoyancy ratio

non-convective zone

pressure....

\section{dimensionless pressure}

Prandtl number

vapor pressure of water at pond's free--surface

partial pressure of water vapor in air.

atmospheric pressure.

heat losses due to convection.

heat losses due to evaporation.

$\left(\mathrm{W} \mathrm{m}^{-2}\right)$

heat losses due to radiation.

$\left(\mathrm{W} \mathrm{m}^{-2}\right)$

total heat losses at the free-surface of the pond

$\left(\mathrm{W} \mathrm{m}^{-2}\right)$

incident solar radiation that reaches the free-surface of the pond.

.. $\left(\mathrm{W} \mathrm{m}^{-2}\right)$

solar radiation that penetrates the free-surface after reflection from pond's

surface.

$\left(\mathrm{W} \mathrm{m}^{-2}\right)$

quantity of solar radiation at depth $\mathrm{z}$.

$\left(\mathrm{W} \mathrm{m}^{-2}\right)$

thermal Rayleigh number

internal Rayleigh number

relative humidity

solutal Rayleigh number

Schmidt number

time

temperature difference.

$. \Delta \mathrm{T}=\mathrm{T}_{\max }-\mathrm{T}_{\text {min }}$

temperature.

temperature of pond's surface

ambient temperature 


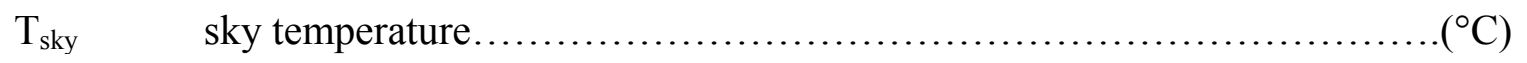

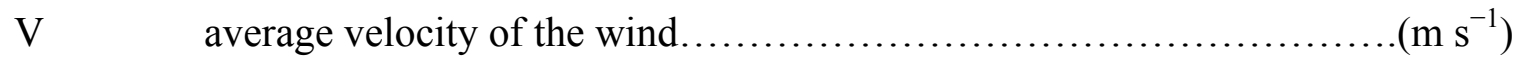

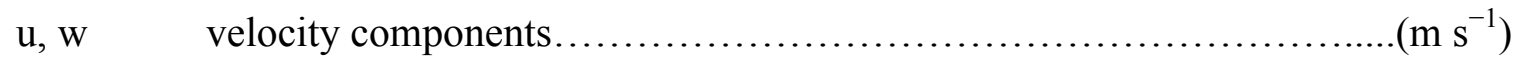

$\mathrm{U}, \mathrm{W}$ dimensionless velocity components

UCZ upper convective zone

$\mathrm{x}, \mathrm{z} \quad$ cartesian coordinates.

$\mathrm{X}, \mathrm{Z} \quad$ dimensionless cartesian coordinates

Greek symbols

\begin{tabular}{|c|c|}
\hline$\alpha$ & thermal diffusivity......................... \\
\hline$\beta_{\mathrm{T}}$ & thermal expansion coefficient............. \\
\hline$\beta_{\mathrm{S}}$ & solutal expansion coefficient........... \\
\hline$\lambda_{\mathrm{w}}$ & water thermal conductivity............ \\
\hline$v$ & cinematic viscosity.... \\
\hline$\mu$ & dynamic viscosity........... \\
\hline$\rho$ & density....................... \\
\hline$\varphi$ & dimensionless concentration \\
\hline$\theta$ & dimensionless temperature \\
\hline$\theta_{\mathrm{i}}$ & angle of incidence over pond's surface... \\
\hline$\theta_{\mathrm{r}}$ & angle of reflection at the pond's surface..... \\
\hline$\tau$ & dimensionless time of heating \\
\hline$\varepsilon$ & extinction coefficient of salty water................................... $\left(\mathrm{m}^{-1}\right)$ \\
\hline$\varepsilon_{\mathrm{W}}$ & emissivity of water \\
\hline$\sigma$ & Stefan-Boltzmann constant..................................... $\left.\mathrm{m}^{-2} \mathrm{~K}^{-4}\right)$ \\
\hline$\Phi_{\mathrm{j}}$ & dimensionless absorption coefficient $\left(\Phi_{\mathrm{j}}=\varepsilon_{\mathrm{j}} \mathrm{H}\right)$ \\
\hline
\end{tabular}

\section{Subscripts}

$\begin{array}{ll}\mathrm{a} & \text { ambient } \\ \mathrm{b} & \text { bottom } \\ \mathrm{W} & \text { water } \\ \mathrm{l} & \text { local } \\ \max & \text { maximum value } \\ \min & \text { minimum value }\end{array}$

\section{Introduction}

Solar radiation constitutes a huge energy source which is abundant and available almost everywhere. A salt gradient solar pond is a large solar energy collection pool which absorbs an important amount of solar energy radiation and stores it as thermal energy in the same medium for a long period of time (months, seasons or even a year). 
Solar ponds can be employed to supply thermal energy in many applications, e.g., heating of buildings, production of electricity, desalination of sea water, textile processing and food industries, etc.

In this work a solar pond was filled with salty water of different concentrations to form three distinct zones. The first convective zone with a minimum salt concentration is called the upper convective zone (UCZ) and is situated on the top of the pond where the incident solar radiation is partially absorbed and the rest is transmitted to the zone below. The second convective zone is situated at the bottom of the solar pond and called lower convective zone (LCZ), which has a high temperature, and a maximum salt concentration. In this zone, solar radiation is absorbed and transformed to thermal energy. Therefore, it is an absorption and storage zone. These two zones are characterized by uniform concentration and separated by the important gradient zone called the non-convective zone which functions as a transparent insulator, permitting solar radiation to be trapped and stored in the bottom of the solar pond. In this zone, the salt concentration and the temperature increase with depth.

The study of solar ponds, including experimental, analytical and numerical investigations, has received much attention from numerous researchers. Kaushika et al. [1] and Bansal et al. [2] solved the one-dimensional equation of heat conduction with fluid internal heating due to solar radiation absorption. Giestas et al. [3] analysed the stability of the gradient zone of a solar pond taking into account solar radiation absorption. Kurt et al. [4] studied the performance of an uninsulated solar pond by developing one-dimensional transient heat conduction with internal heating of fluid. Their research shows that it is possible to store solar energy for a long period of time in a correctly planned solar pond. Hassairi et al. [5] studied experimentally the performance of natural brine solar pond near an area with high average value of solar radiation. They used the brine of Sabkhat el Hadibat in the southern region of Tunisia. In their research, the temperature is mostly uniform in the lower layer and exceeds $45{ }^{\circ} \mathrm{C}$. This temperature decreases near the bottom of the pond due to the heat losses through the soil. For values of solar radiation and ambient temperature equals to $750 \mathrm{Wm}^{-2}$ and $32{ }^{\circ} \mathrm{C}$, the temperature of the lower layer attains a maximum value of $47^{\circ} \mathrm{C}$. Husain et al. [6] studied numerically the thermal behaviour of solar pond. In their research, the temperature of UCZ is estimated by three different approaches. The approaches of Weinberger and Kaushik yield the same temperature while the approach of Joshi and Kishore yielded a smaller temperature. Husain et al. [7] proposed two simple formulations to estimate the solar radiation in a depth of a solar pond and took the universal functions of Hull [8] as a baseline for comparison of accuracy in the estimation of solar radiation. Their results show that the two formulations provide a significant improvement $(20 \%-25 \%)$ in computing time to simulate the thermal performance of a solar pond. Angeli et al. [9] studied numerically the salt diffusion and stability of the density gradient in a solar pond using a one-dimensional transient model. They calculated the optimum thickness of gradient zone and its transient behaviour, taking into account the seasonal solar radiation and the temperature of solar pond. Jaefarzadeh [10] studied the thermal behavior of a salinity gradient solar pond. In this research work, the sensitivity analysis shows the importance of the wall shading effect to reduce the sunny area and the temperature of the LCZ. Mansour et al. [11] studied numerically the temporal evolution of thermal and solute transfer in a three-dimensional solar pond considering the influence of the external factors (solar radiation, wind velocity, ambient temperature, etc.) on its stability characteristics. In their research work, the solar radiation has an important effect on the internal temperature and the stability of the solar pond. The solar heating effect is more important in a poor transparency pond. Mansour et al. [12] studied 
numerically the temporal evolution of thermal and solute transfer in a two-dimensional solar pond considering the influence of the external factors on its long-term thermal and stability characteristics. Their results show that the solar heating effect appears considerably stronger during the spring and summer than during the winter and autumn. Kurt et al. [13] studied experimentally the performance of a small solar pond under simulated solar radiation from two halogen-lamps. Also, they studied numerically the transient thermal and solute behavior in one-dimensional solar pond. In their experimental results, the use of salt (sodium-carbonate) in the density gradient zone permits the storage of a great quantity of solar energy as thermal energy in the LCZ for a long period of time. The numerical temperature difference between the surface and the bottom of the solar pond became higher than the experimental temperature difference. This distinction between the numerical and experimental profiles is caused by the solar simulator radiation. Karakilcik et al. [14] investigated experimentally and numerically the thermal performance of an insulated salt-gradient solar pond. They showed that the performance of the solar pond is affected strongly by the temperature of LCZ and the temperature profile with the depth of the pond. They also established that the introduction of other two zones (upper convective and non-convective) provides many conveniences to calculate the storage efficiency in the LCZ and to determine the relations with heat loads, and a best operating state. Hammami et al. [15] studied numerically the hydrodynamic and thermal behaviours in an enclosure with a vertical solute gradient but they did not take the solar radiation absorption into account. Ould Dah et al. [16] studied experimentally and numerically the performance and stability of a mini solar pond. Their experimental results show an increase of the mini pond daily average temperatures, which reached $54^{\circ} \mathrm{C}$ in the lower convective zone after twenty days. They developed again a one-dimensional model to study the thermal and solute behavior in the mini solar pond. In their research work, the efficiency of the mini solar pond could be improved considerably by using a new method of heat extraction from the NCZ. Suarez et al. [17] studied numerically the effects of double-diffusive convection on the heat performance and stability of a solar pond using a fully coupled two-dimensional model. Wang et al. [18] studied numerically the nonlinear dynamic behavior of the non-convective zone in a salt gradient solar pond. In their research work, the linear and nonlinear studies indicate that oscillation is a narrow region above the stable region. The nonlinear results indicate that the linear stability analysis leans to a larger upper boundary in the oscillatory regions.

In the previous studies, no attempt was made to describe the velocity, temperature and concentration field distributions in the salt-gradient solar pond. Hence, the temperature and the concentration are commonly assumed to be uniform in the entire of the LCZ and the UCZ, which is undoubtedly a simplifying hypothesis. Also, the effect of buoyancy ratio on the pond stability has not been studied.

Here, we present a two-dimensional numerical modelling of the hydrodynamic, heat and mass transfers in a salt-gradient solar pond and its stability. The pond is filled with salty water of different salinities to form three distinct salty water zones (upper convective, non-convective and lower convective). The movements of salty water are created in the UCZ and in the LCZ by double-diffusive natural convection induced by an internal heating process due to solar radiation absorption. Our objective is to supply by computations detailed knowledge of the hydrodynamic, thermal and solutal structures of the transient fluid flow developed in a salt-gradient solar pond during the collection and the storage of energy. 
The resolution of continuity, momentum, thermal energy and mass transfer equations governing the hydrodynamic, heat and mass transfer developed in the solar pond is conducted using finite-volume method discretization in transient regime.

This numerical study is divided into six sections: Section 1 introduces the importance of salt-gradient solar ponds to store a large amount of solar energy and their various applications. Section 2 describes the configuration of the insulated solar pond and necessary simplifying assumptions. Section 3 presents the equations of continuity, momentum, thermal energy and mass transfer governing the transient hydrodynamic, heat and mass transfer in the solar pond with internal heating of the fluid due to solar radiation absorption. Section 4 describes the numerical method used in this work and validates the numerical code specifically developed for the problem of this study. Section 5 discussed the effect of buoyancy ratio on the stability of the solar pond and on the average temperature and concentration profiles. This section analyzes again the effects of UCZ, NCZ and LCZ thicknesses on the thermal behaviour of the solar pond. The numerical study concludes in Section 6 .

\section{Physical Model and Simplifying Assumptions}

The body of the simulated solar pond is a two-dimensional rectangular enclosure of height $\mathrm{H}$ and length $\mathrm{L}$ filled with a mixture of water and salt. Figure 1 shows the physical model of the solar pond under consideration.

Figure 1. Schematic view of the insulated salt gradient solar pond.

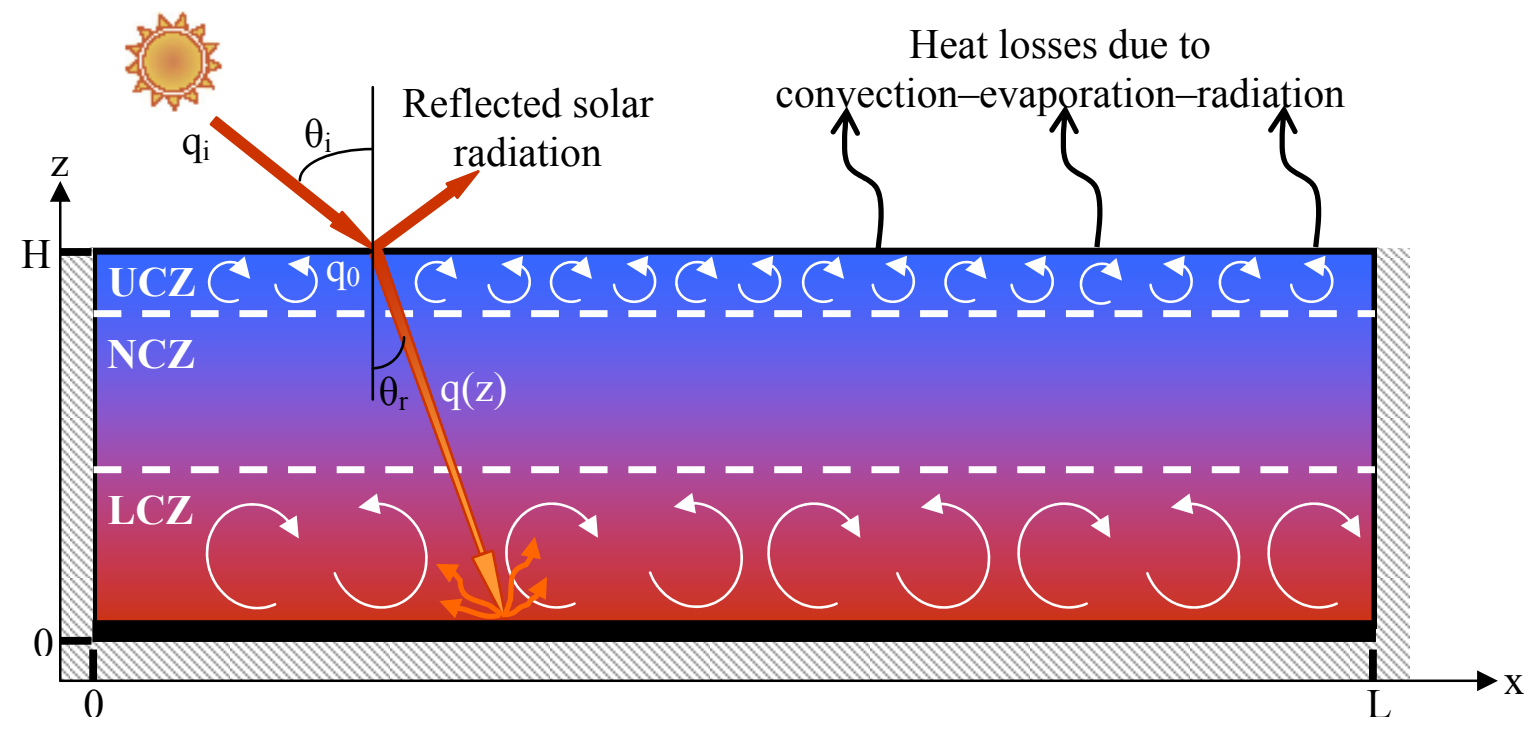

Because different processes are occurring inside and outside the salt gradient solar pond, the operation of the solar pond is frequently complicated, so some assumptions were made to simplify the analysis of the hydrodynamic, thermal and solute behavior of the solar pond. The third dimension of the enclosure is assumed to be large enough so that the fluid flow, heat and mass transfer are two-dimensional. The fluid is assumed to be Newtonian and incompressible. The solar pond is constituted by three distinct zones: LCZ, NCZ and UCZ. The vertical walls of the solar pond are well insulated and impermeable. The free-surface of the solar pond is subjected to heat losses by 
convection, evaporation and radiation, and is impermeable. As shown in Figure 1, a portion of solar radiation entering the pond is absorbed by the pond's bottom and converted to thermal energy which is stored in the lower region of the solar pond. The bottom of the pond is painted in black in order to increase the solar radiation absorption. The bottom is assumed to be adiabatic and impermeable. The thermo-physical properties of the salty water do not vary with temperature and salt concentration, except density in the buoyancy term, which depends linearly on both local temperature and concentration, i.e., the Boussinesq approximation is assumed to be valid:

$$
\rho(T, C)=\rho_{0}\left(1-\beta_{T}\left(T-T_{a}\right)+\beta_{S}\left(C-C_{\text {min }}\right)\right)
$$

where $\beta_{\mathrm{T}}=-1 / \rho_{0}[\partial \rho / \partial \mathrm{T}]_{\mathrm{C}}$ and $\beta_{\mathrm{S}}=-1 / \rho_{0}[\partial \rho / \partial \mathrm{C}]_{\mathrm{T}}$.

The height of the pond $(\mathrm{H})$ is taken as a reference length for the spatial coordinates $(\mathrm{X}=\mathrm{x} / \mathrm{H}$; $\mathrm{Z}=\mathrm{z} / \mathrm{H})$. The references for time, velocity, pressure, temperature and concentration are defined as follows: $\mathrm{H}^{2} / \alpha, \alpha / \mathrm{H}, \rho \alpha^{2} / \mathrm{H}^{2}, \Delta \mathrm{T}$ and $\Delta \mathrm{C}$, respectively.

\section{Mathematical Model for the Salt Gradient Solar Pond}

The quantity, $q(\mathrm{z})$, of solar radiation at different depths of salty water in the solar pond can be expressed as [19]:

$$
q(z)=\mathrm{kq}_{0} \sum_{j=1}^{4} \gamma_{j} \exp \left[-\frac{\varepsilon_{j}}{\cos \theta_{r}}(H-z)\right]
$$

where $\mathrm{q}_{0}$ represents the solar radiation that penetrates the free-surface of the solar pond, which is given by:

$$
\mathrm{q}_{0}=(1-\mathrm{r}) \mathrm{q}_{\mathrm{i}}
$$

where $q_{i}$, is the incident solar radiation that reaches the free-surface of the solar pond and $r$ is the reflectance of solar radiation at the free-surface of the pond. This coefficient is obtained from [20]:

$$
r=0.5\left[\frac{\tan ^{2}\left(\theta_{i}-\theta_{r}\right)}{\tan ^{2}\left(\theta_{i}+\theta_{r}\right)}+\frac{\sin ^{2}\left(\theta_{i}-\theta_{r}\right)}{\sin ^{2}\left(\theta_{i}+\theta_{r}\right)}\right]
$$

where $\theta_{\mathrm{i}}$ is the angle of incidence; $\theta_{\mathrm{r}}$ is the angle of reflection and $\mathrm{k}$ is a coefficient due to the effects of salt concentration, propagation of radiation in the layers of salty water and turbidity of water on the reduction of solar radiation. For the present study, $\theta_{\mathrm{i}}=60^{\circ}$ and $\mathrm{r}=0.06$ [21]. So, $\theta_{\mathrm{r}}=40.5^{\circ}$ is obtained from Equation (4). The coefficient $\mathrm{k}$ is equal to 0.85 [10]. $\gamma_{\mathrm{j}}$ and $\varepsilon_{\mathrm{j}}$ are dependent on the absorption of the particular wavelengths range of the arriving solar radiations. These constants $\gamma_{j}$ and $\varepsilon_{j}$ are as follows [10,22] (Table 1):

Table 1. Constants $\gamma_{\mathrm{j}}$ and $\varepsilon_{\mathrm{j}}$.

\begin{tabular}{ccc}
\hline Wavelength & $\boldsymbol{\gamma}$ & $\boldsymbol{\varepsilon}$ \\
\hline $0.2-0.6$ & 0.237 & 0.032 \\
$0.6-0.75$ & 0.193 & 0.45 \\
$0.75-0.9$ & 0.167 & 3 \\
$0.9-1.2$ & 0.179 & 35 \\
\hline
\end{tabular}


Finally, Equation (2) is expressed as follows:

$$
q(Z)=0.85 q_{0} \sum_{j=1}^{4} \gamma_{j} \exp \left[-\frac{\Phi_{j}}{0.76}(1-Z)\right]
$$

Under the above assumptions, the transient hydrodynamic, heat and mass transfer process in the solar pond with internal heating of the fluid due to solar radiation absorption is governed by continuity, momentum, thermal energy and mass transfer equations:

$$
\begin{gathered}
\operatorname{div} \vec{v}=0 \\
\frac{\partial u}{\partial t}+\operatorname{div}(u \vec{v}-v \overrightarrow{\operatorname{grad} u})=-\frac{1}{\rho_{0}} \frac{\partial p}{\partial x} \\
\frac{\partial \mathrm{w}}{\partial \mathrm{t}}+\operatorname{div}(\mathrm{w} \overrightarrow{\mathrm{v}}-v \overrightarrow{\operatorname{grad} \mathrm{w}})=-\frac{1}{\rho_{0}} \frac{\partial \mathrm{p}}{\partial \mathrm{z}}+\left[\beta_{\mathrm{T}}\left(\mathrm{T}-\mathrm{T}_{\mathrm{a}}\right)-\beta_{\mathrm{C}}\left(\mathrm{C}-\mathrm{C}_{\min }\right)\right] \mathrm{g} \\
\frac{\partial \mathrm{T}}{\partial \mathrm{t}}+\operatorname{div}(\mathrm{T} \overrightarrow{\mathrm{v}}-\alpha \overrightarrow{\operatorname{grad} \mathrm{T}})=\frac{\mathrm{S}_{\mathrm{R}}}{\rho_{\mathrm{p}}} \\
\frac{\partial \mathrm{C}}{\partial \mathrm{t}}+\operatorname{div}(\mathrm{C} \overrightarrow{\mathrm{v}}-\mathrm{D} \overrightarrow{\operatorname{grad} C})=0
\end{gathered}
$$

In Equation (9), the term $S_{R}$ represents the rate of energy generation per unit volume in a fluid layer, which results from the solar radiation absorption by salty water. It is given by:

$$
\mathrm{S}_{\mathrm{R}}=\frac{\partial \mathrm{q}(\mathrm{z})}{\partial \mathrm{z}}=0.85 \mathrm{q}_{0} \sum_{\mathrm{j}=1}^{4} \frac{\gamma_{\mathrm{j}} \varepsilon_{\mathrm{j}}}{0.76} \exp \left[-\frac{\varepsilon_{\mathrm{j}}}{0.76}(\mathrm{H}-\mathrm{z})\right]
$$

Introducing the following dimensionless groups defined by:

$$
X=\frac{x}{H}, Z=\frac{z}{H}, U=\frac{u H}{\alpha}, W=\frac{w H}{\alpha}, \theta=\frac{T-T_{a}}{\Delta T}, \varphi=\frac{C-C_{\min }}{\Delta C}, P=\frac{p H^{2}}{\rho_{0} \alpha^{2}}, \tau=\frac{\alpha t}{H^{2}}
$$

The dimensionless equations of continuity, momentum, thermal energy and mass transfer can be written as follows:

$$
\begin{gathered}
\operatorname{div} \vec{V}=0 \\
\frac{\partial U}{\partial \tau}+\operatorname{div}(U \vec{V}-\operatorname{Pr} \overrightarrow{\operatorname{grad}} U)=-\frac{\partial P}{\partial X} \\
\frac{\partial W}{\partial \tau}+\operatorname{div}(W \vec{V}-\operatorname{Pr} \overrightarrow{\operatorname{grad}} \mathrm{W})=-\frac{\partial P}{\partial Z}+\operatorname{Pr}_{\operatorname{Ra}}(\theta-N \varphi) \\
\frac{\partial \theta}{\partial \tau}+\operatorname{div}(\theta \vec{V}-\overrightarrow{\operatorname{grad}} \theta)=0.85 \frac{\operatorname{Ra}_{I}}{\operatorname{Ra}_{\mathrm{T}}} \sum_{\mathrm{j}=1}^{4} \frac{\gamma_{\mathrm{j}} \Phi_{j}}{0.76} \exp \left[-\frac{\Phi_{j}}{0.76}(1-\mathrm{Z})\right] \\
\frac{\partial \varphi}{\partial \tau}+\operatorname{div}\left(\varphi \overrightarrow{\mathrm{V}}-\frac{1}{\operatorname{Le}} \overrightarrow{\operatorname{grad} \varphi}\right)=0
\end{gathered}
$$

The dimensionless parameters that characterize the salt gradient solar pond are the aspect ratio $\mathrm{A}=\mathrm{L} / \mathrm{H}$, the thermal Rayleigh number $\mathrm{Ra}_{\mathrm{T}}=\mathrm{g} \beta_{\mathrm{T}} \Delta \mathrm{TH}^{3} /(\alpha v)$, the internal Rayleigh number $\mathrm{Ra}_{\mathrm{I}}=\mathrm{g} \beta_{\mathrm{T}} \mathrm{q}_{0} \mathrm{H}^{4} /\left(\lambda_{\mathrm{w}} \alpha v\right)$, the solutal Rayleigh number $\mathrm{Ra}_{\mathrm{S}}=\mathrm{g} \beta_{\mathrm{S}} \Delta \mathrm{CH}^{3} /(\alpha v)$, the buoyancy ratio 
$\mathrm{N}=\beta_{\mathrm{S}} \Delta \mathrm{C} /\left(\beta_{\mathrm{T}} \Delta \mathrm{T}\right)$, the Prandtl number $\operatorname{Pr}=v / \alpha$, the Schmidt number $\mathrm{Sc}=v / \mathrm{D}$ and the Lewis number $\mathrm{Le}=\mathrm{Sc} / \mathrm{Pr}$.

Initially, the fluid is considered in rest condition and at ambient temperature, so the dimensionless temperature, pressure and velocities have initial values equal to zero. The solar pond is initially $(\tau=0)$ filled with water and subdivided into three zones in where the dimensionless salt concentrations are as follows:

$\begin{array}{cc}\text { Zone } & \varphi \\ \text { LCZ } & 1 \\ \mathrm{NCZ} & \left(\mathrm{Z}_{\mathrm{NCZ}}-\mathrm{Z}\right) /\left(\mathrm{Z}_{\mathrm{NCZ}}-\mathrm{Z}_{\mathrm{LCZ}}\right) \\ \mathrm{UCZ} & 0\end{array}$

The boundary conditions on the vertical walls and on the bottom of the pond are: $U=W=0$. The vertical walls of the pond are supposed to be adiabatic and impermeable. At the bottom and the free-surface of the solar pond, we imposed a zero flux of mass. The boundary condition for velocities on the free-surface is: $\partial \mathrm{U} / \partial \mathrm{Z}=0$ and $\mathrm{W}=0$. For reasons of symmetry, we consider only the half of the pond:

$$
\begin{gathered}
\frac{\partial \theta}{\partial X}=0, \frac{\partial \varphi}{\partial X}=0 \text { at } X=0 \\
U=0, \frac{\partial W}{\partial X}=0, \frac{\partial \theta}{\partial X}=0, \frac{\partial \varphi}{\partial X}=0 \text { at } X=A / 2
\end{gathered}
$$

The boundary conditions for heat flux at the bottom and the free-surface of the solar pond are detailed in Appendi

\section{Numerical Method and Validation}

Equations (13-17) were solved using the finite-volume method developed by [23]. The discretization method and numerical solution procedure used have been described in detail elsewhere [24]. Only the main features are given here. First, the domain of the enclosure is subdivided in elementary volumes $\Omega_{\Phi}$ defined in a Cartesian two-dimensional coordinates. The transport equation is then integrated in each of these volumes, expressing the balance of flux " $J_{\Phi}$ " of the transport parameter " $\Phi$ " which represents the components of velocity vector ( $U$ and $W)$, temperature $(\theta)$ or concentration $(\varphi)$ :

$$
\iiint_{\Omega_{\Phi}} \frac{\partial \Phi}{\partial \tau} \mathrm{d} v=-\iiint_{\Omega_{\Phi}} \operatorname{div} \vec{J}_{\Phi} \mathrm{d} v+\iiint_{\Omega_{\Phi}} \mathrm{S}_{\Phi} \mathrm{d} v
$$

The volume integral of the divergence of $\vec{J}_{\Phi}$ is changed into surface integral:

$$
\iiint_{\Omega_{\Phi}} \frac{\partial \Phi}{\partial \tau} \mathrm{d} v=-\iint_{\Sigma} \overrightarrow{\mathbf{J}}_{\Phi} \overrightarrow{\mathrm{n}} \mathrm{ds}+\iiint_{\Omega_{\Phi}} \mathrm{S}_{\Phi} \mathrm{d} v
$$

where $\Sigma$ is the surface area covering the control volume $\Omega_{\Phi} ; \vec{n}$ is the outward unit normal to the differential surface area ds and $\vec{J}_{\Phi}$ represents the flux term of $\Phi$, which is expressed by:

$$
\overrightarrow{\mathrm{J}}_{\Phi}=\Phi \overrightarrow{\mathrm{V}}-\Gamma_{\Phi} \overrightarrow{\mathrm{grad}} \Phi
$$


where $\Gamma_{\Phi}$ is the diffusion coefficient; and $\mathrm{S}_{\Phi}$ a source term evaluated explicitly.

The definition of $\Phi, \Gamma_{\Phi}, \mathrm{S}_{\Phi}$ and of the flux term $\overrightarrow{\mathbf{J}}_{\Phi}$ for each equation is given, in dimensionless form, in Table 2 .

Table 2. Diffusion coefficients, flux and source terms of variable $\Phi$.

\begin{tabular}{cccc}
\hline$\Phi$ & $\Gamma_{\Phi}$ & $\overrightarrow{\mathrm{J}}_{\Phi}$ & $\mathrm{S}_{\Phi}$ \\
\hline 1 & 1 & $\overrightarrow{\mathrm{V}}$ & 0 \\
$\mathrm{U}$ & $\operatorname{Pr}$ & $\mathrm{U} \overrightarrow{\mathrm{V}}-\Gamma_{\mathrm{U}} \overrightarrow{\operatorname{grad}} \mathrm{U}$ & $-\partial \mathrm{P} / \partial \mathrm{X}$ \\
$\mathrm{W}$ & $\operatorname{Pr}$ & $\mathrm{W} \overrightarrow{\mathrm{V}}-\Gamma_{\mathrm{W}} \overrightarrow{\operatorname{grad}} \mathrm{W}$ & $-\partial \mathrm{P} / \partial \mathrm{Z}+\operatorname{Pr} \operatorname{Ra}_{\mathrm{T}}(\theta-\mathrm{N} \varphi)$ \\
$\theta$ & 1 & $\theta \overrightarrow{\mathrm{V}}-\Gamma_{\theta} \overrightarrow{\operatorname{grad}} \theta$ & $0.85 \mathrm{Ra}_{\mathrm{I}} / \mathrm{Ra}_{\mathrm{T}} \sum_{\mathrm{j}=1}^{4}\left(\gamma_{\mathrm{j}} \Phi_{\mathrm{j}} / 0.76\right) \exp \left[-\Phi_{\mathrm{j}}(1-\mathrm{Z}) / 0.76\right]$ \\
$\varphi$ & $1 / \mathrm{Le}$ & $\varphi \overrightarrow{\mathrm{V}}-\Gamma_{\varphi} \overrightarrow{\operatorname{grad}} \varphi$ & 0 \\
\hline
\end{tabular}

Using a staggered grid, three different control volumes are defined for a given node point: one for each of the two vector components and one for the scalar variables. Then, each of the transport equations is integrated over its own control volume. The spatial discretization of the governing equations is obtained using the hybrid scheme interpolation.

The temporal integration over a time step has begun using the Alterning Directions Implicit (ADI) method (Peaceman and Rachford [25]) which produces two separate tridiagonal matrices for each equation.

The pressure-velocity coupling was handled by the Semi-implicit Method for Pressure-linked Equation Revised (SIMPLER) algorithm [23]. This algorithm consists of correcting velocities predicted with the momentum equations. As the pressure correction equation is solved until convergence, we obtain the pressure field, and therefore the estimated velocities are corrected to fit the equation of continuity.

A computational domain consisting of $50 \times 100$ grid points with uniform grid spacing in $\mathrm{OX}$ and in $\mathrm{OZ}$ directions and a dimensionless time step equal to $10^{-8}$ were found to be sufficient for producing accurate results at reasonable computed time.

In order to check on the accuracy of the numerical code specifically developed for the solution of the problem considered in the present work, it was validated by performing computational simulation for double-diffusive natural convection, which is reported earlier by Han and Kuehn [26] and Suarez et al. [17]. In this case, Figure 2 shows comparison for velocities, temperature and concentration fields of the present numerical study and the numerical results published by Han and Kuehn [26], and Suarez et al. [17]. Computations are performed for opposing buoyancy conditions with the constant following parameters: $\mathrm{Ra}_{\mathrm{T}}=3.2 \times 10^{6}, \mathrm{Ra}_{\mathrm{S}}=2.4 \times 10^{7}, \mathrm{~A}=1 / 4, \mathrm{Sc}=2000$ and $\operatorname{Pr}=8$. Figure 2 shows a good agreement between both results. 
Figure 2. Comparison of velocities, temperature $(\theta)$ and concentration $(\varphi)$ fields between the present study (a) and previous studies reported by Suarez et al. [17] (b), and Han and Kuehn [26] (c); $\left(\mathrm{Ra}_{\mathrm{T}}=3.2 \times 10^{6}, \mathrm{Ra}_{\mathrm{S}}=2.4 \times 10^{7}, \mathrm{~A}=1 / 4, \mathrm{Sc}=2000\right.$ and $\left.\operatorname{Pr}=8\right)$.
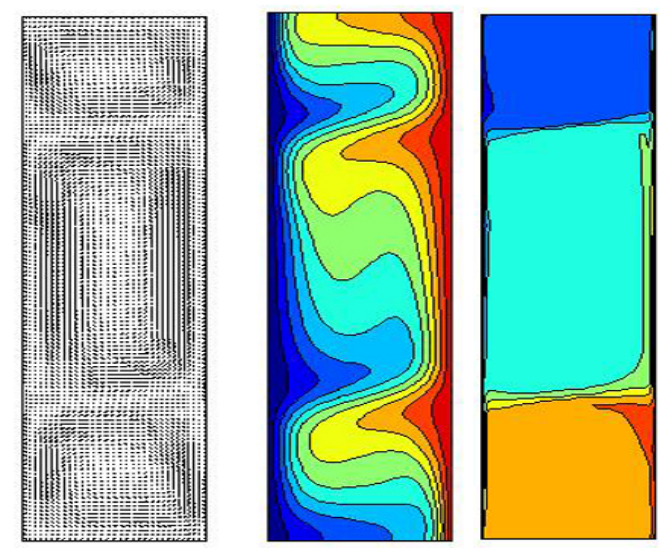

(a)
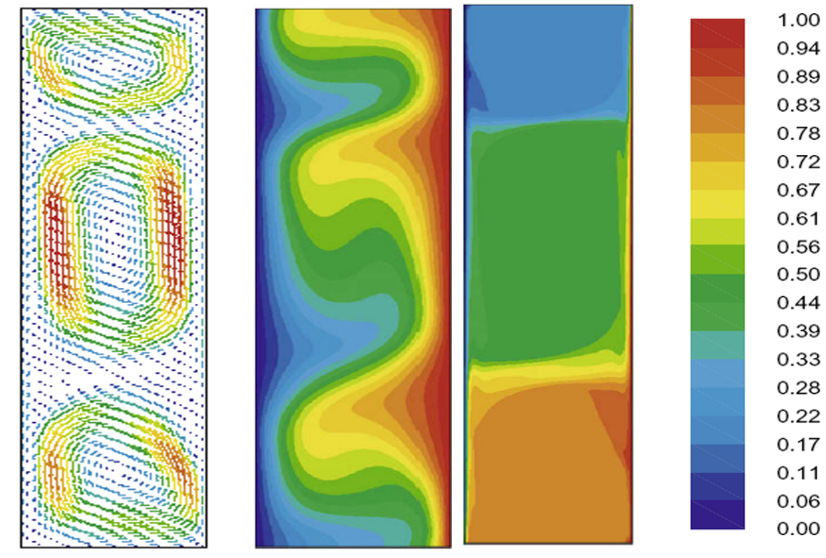

(b)

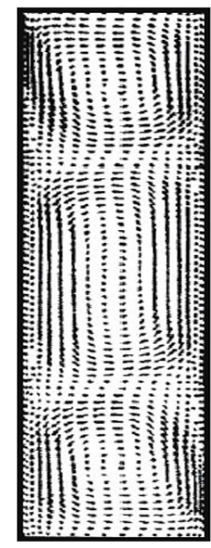

(velocities)

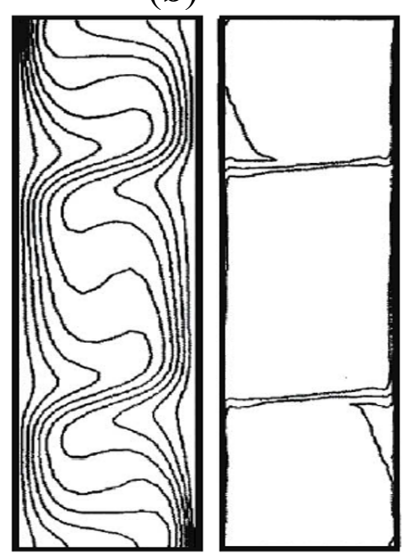

$(\theta)$

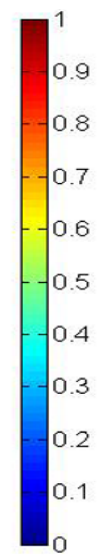

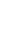

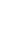


These numerical results are given for constant values of the Prandtl number $\operatorname{Pr}=6$ and the Schmidt number $\mathrm{Sc}=1000$, which correspond to the average characteristics of salt-water mixtures. The results are generated for a thermal Rayleigh number $\mathrm{Ra}_{\mathrm{T}}=10^{7}$ and an internal Rayleigh number $\mathrm{Ra}_{\mathrm{I}}=1.4 \times 10^{8}$.

\subsection{Effect of Buoyancy Ratio on the Stability of Solar Pond}

The effect of buoyancy ratio on the distribution of temperature, concentration and velocities in a solar pond is represented in Figures $3-5$ at $\tau=0.05$ and for $\mathrm{Ra}_{\mathrm{T}}=10^{7}, \mathrm{Ra}_{\mathrm{I}}=1.4 \times 10^{8}, \operatorname{Pr}=6$, $\mathrm{Sc}=1000$ and $\mathrm{A}=3$. Figure 3 shows the evolution of temperature distribution with the buoyancy ratio in a salt-gradient solar pond.

Figure 3. Evolution of temperature field with the buoyancy ratio $[(\mathbf{a}) \mathrm{N}=0 ;$ (b) $\mathrm{N}=1$; (c) $\mathrm{N}=2 ;$ (d) $\mathrm{N}=10$ ] in a salt-gradient solar pond at $\tau=0.05$ and for $\mathrm{Ra}_{\mathrm{T}}=10^{7}$, $\mathrm{Ra}_{\mathrm{I}}=1.4 \times 10^{8}, \mathrm{Pr}=6, \mathrm{Sc}=1000$ and $\mathrm{A}=3$.

(a)

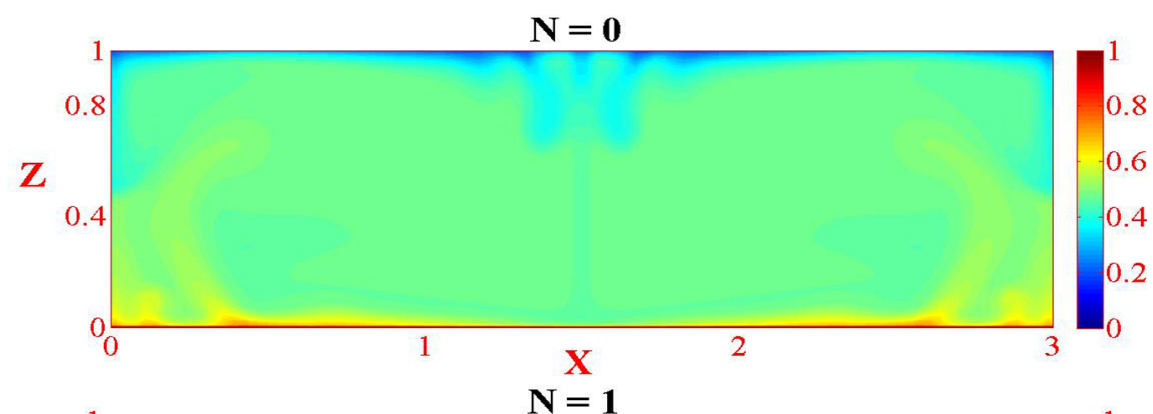

(b)

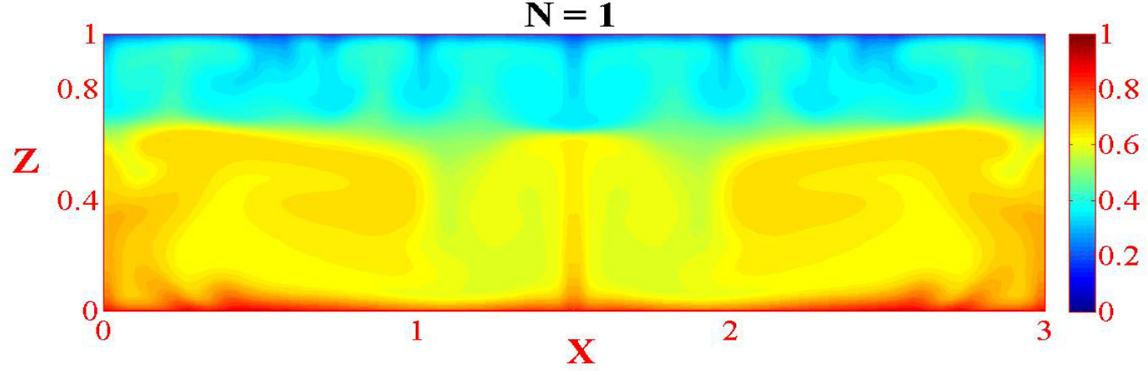

(c)

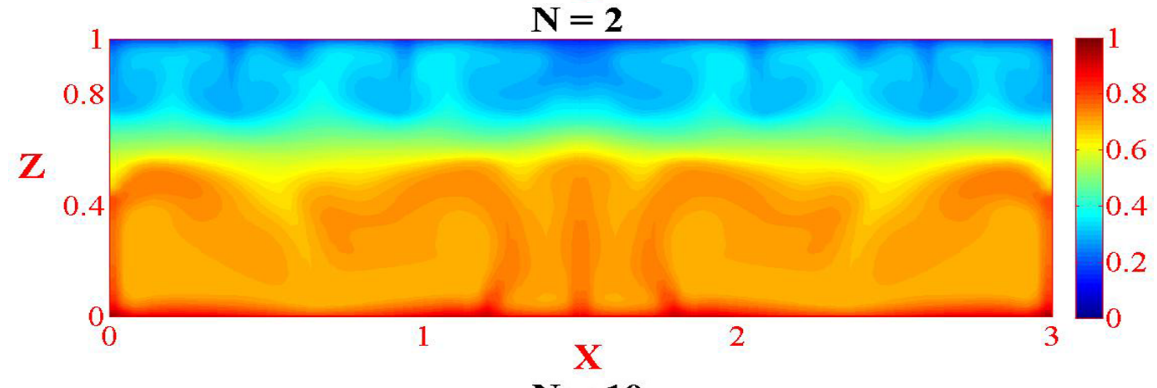

(d)

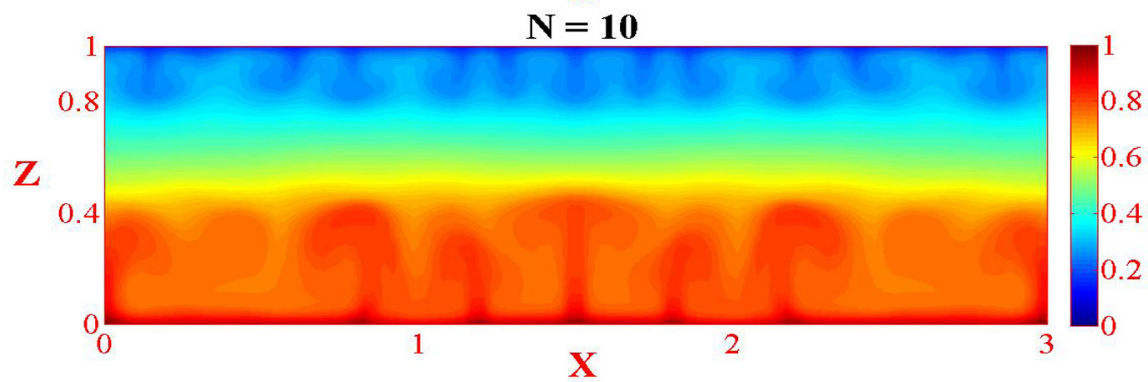

For $\mathrm{N}=0$ (Figure 3), the flow of the fluid is motivated only by the thermal buoyancy force. Part of incident solar radiation absorbed at the bottom of the pond warms the pure water in the lower region of 
the pond. The hot water rises to the free-surface where it loses some of its heat by convection, evaporation and radiation. The cold water, becoming heavier, sinks to the bottom again. Because of this continuous mixing and heat losses, it is impossible to store solar energy as thermal energy in the lower region of the pond. For a buoyancy ratio $\mathrm{N}=1$, the competition between thermal and solute buoyancy forces becomes the same order of magnitude and the convection movements induced by the absorption of solar radiation prevent the storage of solar energy in the bottom of the convective solar pond. For $\mathrm{N}=2$, irregular NCZ begins to be formed. When the buoyancy ratio reaches a value equal to 10 , diffusion dominates heat transfer in the solar pond, so the convection currents are suppressed in the $\mathrm{NCZ}$ and the considerable quantity of solar energy radiation trapped in the LCZ is stored as thermal energy in the same zone. Figure 3 shows again that the temperature is decreased in the UCZ and increased in the LCZ when the buoyancy ratio increases from zero to ten. Figure 4 shows the concentration distribution in a salt-gradient solar pond at the same time of heating $\tau=0.05$ and for different buoyancy ratios.

Figure 4. Evolution of concentration field with the buoyancy ratio [(a) $\mathrm{N}=1$; (b) $\mathrm{N}=2$; (c) $\mathrm{N}=10]$ in a salt-gradient solar pond at $\tau=0.05$ and for $\mathrm{Ra}_{\mathrm{T}}=10^{7}, \mathrm{Ra}_{\mathrm{I}}=1.4 \times 10^{8}$, $\operatorname{Pr}=6, \mathrm{Sc}=1000$ and $\mathrm{A}=3$.

(a)

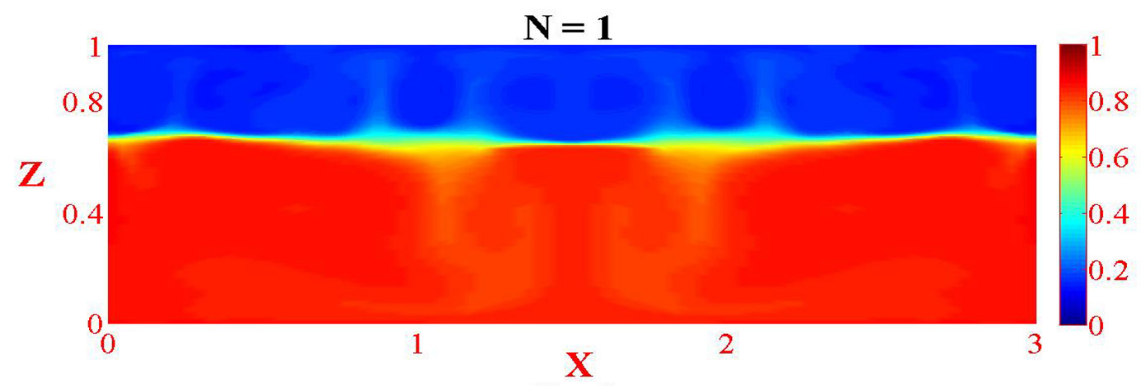

(b)

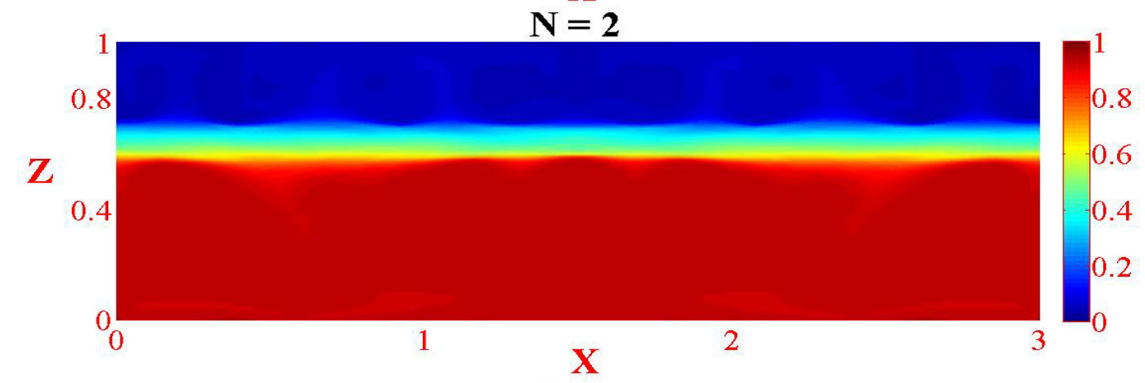

(c)

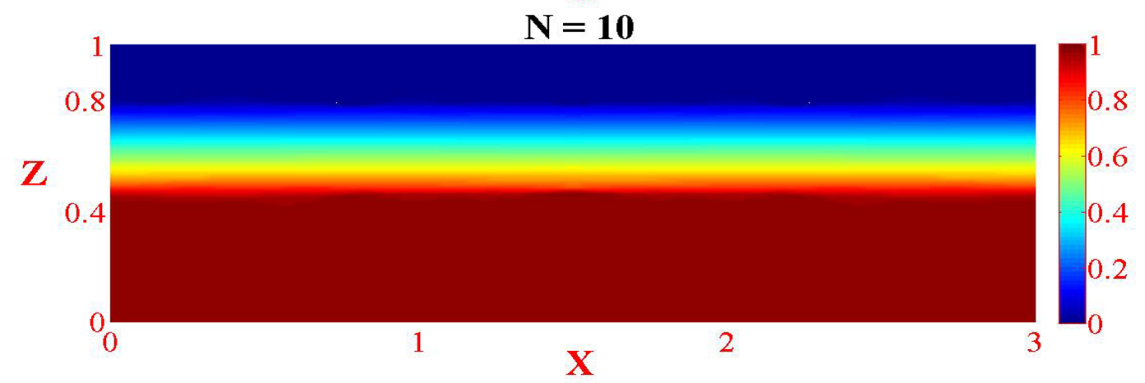

Figure 4 shows that the concentration of salt is disturbed in the solar pond when the buoyancy ratio is equal to 1 . For a buoyancy ratio equal to 2 , a stratification of fluid layers tends to be established. When the buoyancy ratio reaches a value equal to 10 , diffusion dominates mass transfer and the salt 
concentration remains invariable, which indicates that the stratified fluid layers in the solar pond are still stable.

In order to understand the effect of buoyancy ratio on the hydrodynamic behaviour of the solar pond during the absorption of solar radiation, we have established the distribution of velocities in a salt-gradient solar pond at the same time of heating $\tau=0.05$ and for different buoyancy ratios (Figure 5).

Figure 5. Evolution of velocities field with the buoyancy ratio $[(\mathbf{a}) \mathrm{N}=1$; (b) $\mathrm{N}=2$; (c) $\mathrm{N}=10$; (d,e) zoom of velocity vectors] in a salt-gradient solar pond at $\tau=0.05$ and for $\mathrm{Ra}_{\mathrm{T}}=10^{7}, \mathrm{Ra}_{\mathrm{I}}=1.4 \times 10^{8}, \mathrm{Pr}=6, \mathrm{Sc}=1000$ and $\mathrm{A}=3$.

(a)

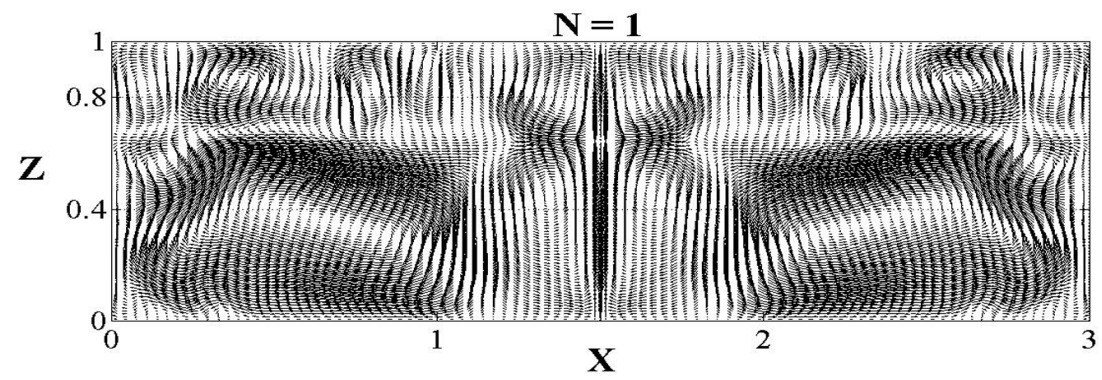

(b)

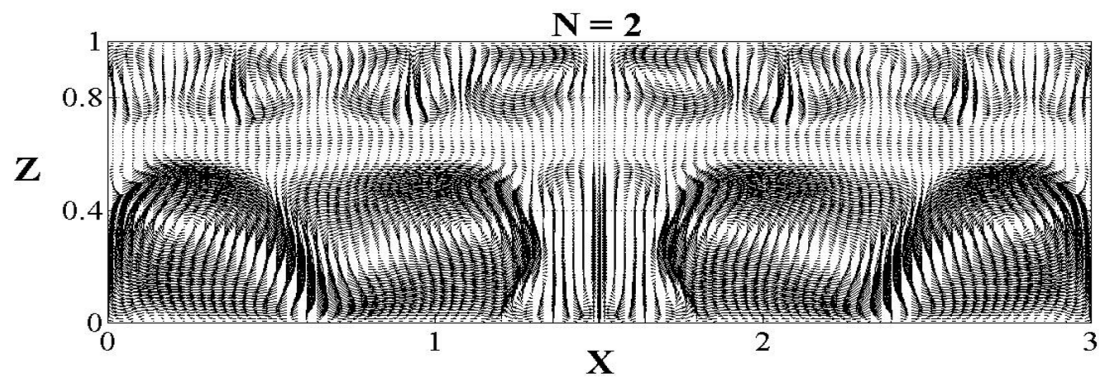

$\mathrm{X}$

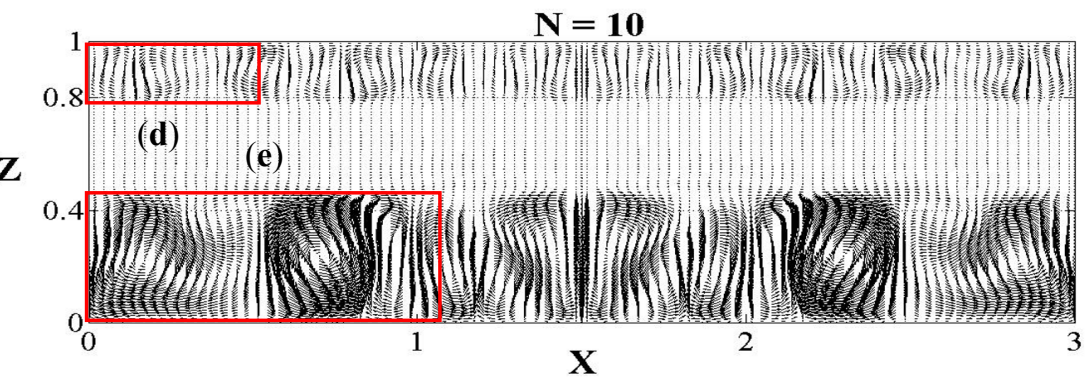

(c)

(d)

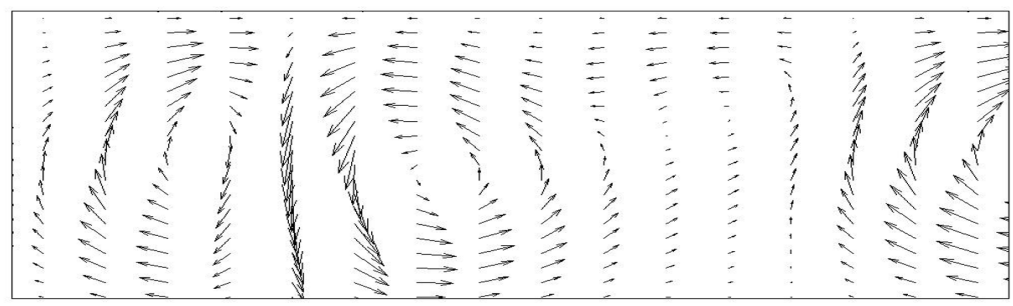

(e)

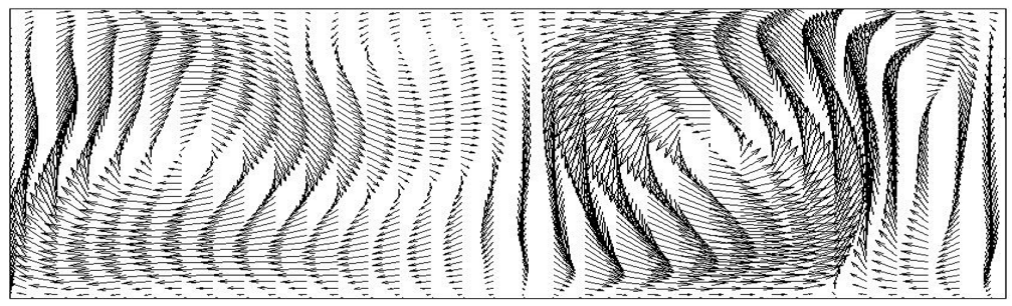


It is interesting to observe that for $\mathrm{N}=1$, there exists little recirculation of fluid in the $\mathrm{UCZ}$ and large fluid recirculations occupying the LCZ and the NCZ. For $\mathrm{N}=2$, the convective cells are suppressed in the middle of NCZ. For a buoyancy ratio equal to 10, diffusion dominates thermal and solute transfer and the flow is suppressed in the NCZ. Then, a succession of small eddies are generated in the upper convective zone and in the lower convective zone where the flow results from the competition between thermal and solute buoyancy forces.

\subsection{Effect of Buoyancy Ratio on the Temperature and Concentration Profiles}

Figures 6 and 7 show the evolution of the average temperature and concentration profiles with the buoyancy ratio in the solar pond at a solar heating time $\tau=0.05$ and for $\mathrm{Ra}_{\mathrm{T}}=10^{7}, \mathrm{Ra}_{\mathrm{I}}=1.4 \times 10^{8}$, $\operatorname{Pr}=6, \mathrm{Sc}=1000$ and $\mathrm{A}=3$. The buoyancy ratio is important to prevent convective motions induced by the absorption of solar radiation where the increase of this parameter will reduce the upwards heat losses. In this case, Figure 6 shows that the average temperature profile is decreased in the UCZ and increased in the LCZ when the buoyancy ratio is increased.

Figure 6. Effect of buoyancy ratio on the average temperature profile in a salt-gradient solar pond at $\tau=0.05$ and for $\mathrm{Ra}_{\mathrm{T}}=10^{7}, \mathrm{Ra}_{\mathrm{I}}=1.4 \times 10^{8}, \mathrm{Pr}=6, \mathrm{Sc}=1000$ and $\mathrm{A}=3$.

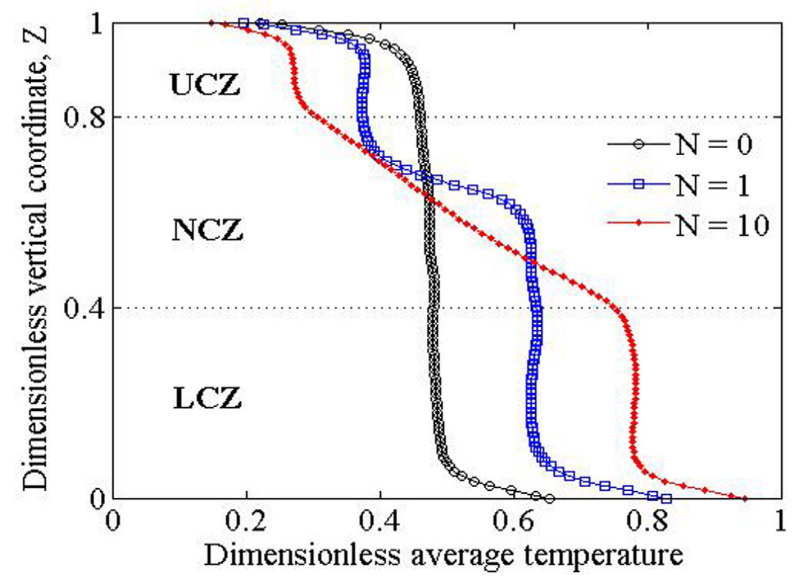

Figure 7. Effect of buoyancy ratio on the average concentration profile in a salt-gradient solar pond at $\tau=0.05$ and for $\mathrm{Ra}_{\mathrm{T}}=10^{7}, \mathrm{Ra}_{\mathrm{I}}=1.4 \times 10^{8}, \mathrm{Pr}=6, \mathrm{Sc}=1000$ and $\mathrm{A}=3$.

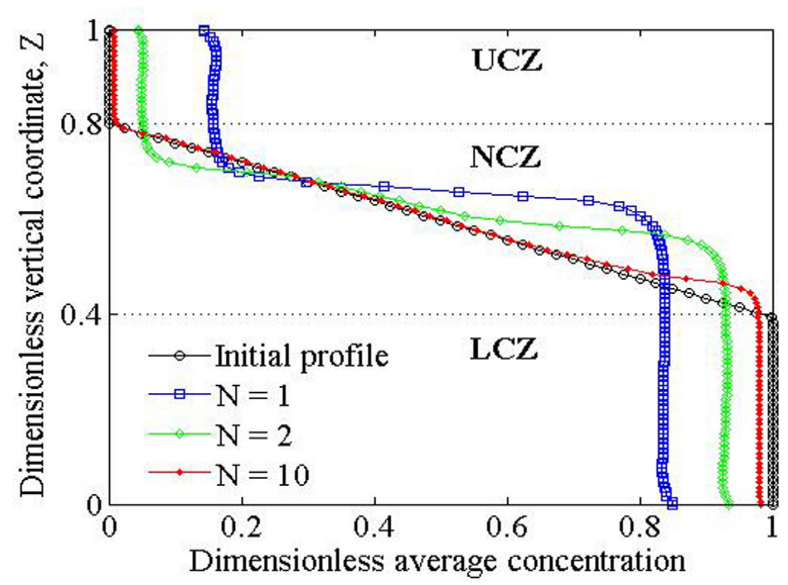


Figure 7 indicates that the increase in the buoyancy ratio will decrease the profile of the average concentration in the UCZ to reach the value of zero. In the LCZ, this profile is increased almost to one.

For $\mathrm{N}=10$, Figure 7 shows again that the average concentration profile is practical confused with the initial profile. This implies that the stratified solute layers remain stable.

The evolution of dimensionless average temperature and salt concentration of UCZ and LCZ with the buoyancy ratio are shown in the Figures 8 and 9. Figure 8 indicates clearly that the increase of the buoyancy ratio will decrease the average temperature in the UCZ and will increase this temperature in the LCZ.

Figure 8. Effect of buoyancy ratio on the average temperature of UCZ and LCZ in a salt-gradient solar pond at $\tau=0.05$ and for $\mathrm{Ra}_{\mathrm{T}}=10^{7}, \mathrm{Ra}_{\mathrm{I}}=1.4 \times 10^{8}, \mathrm{Pr}=6, \mathrm{Sc}=1000$ and $\mathrm{A}=3$.

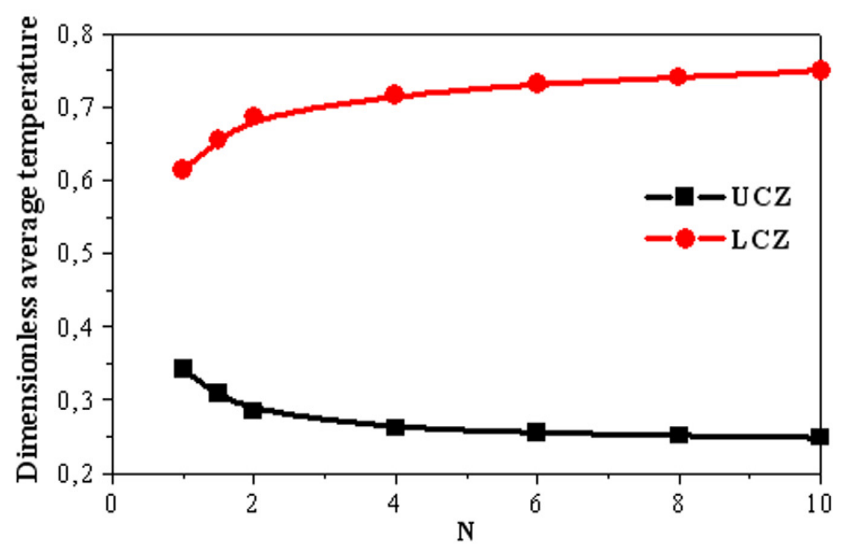

Figure 9 shows clearly that the increase of the buoyancy ratio will decrease the average salt concentration to almost zero in the UCZ and will increase this salt concentration in the LCZ to reach a value near one.

Figure 9. Effect of buoyancy ratio on the average concentration of UCZ and LCZ in a salt-gradient solar pond at $\tau=0.05$ and for $\mathrm{Ra}_{\mathrm{T}}=10^{7}, \mathrm{Ra}_{\mathrm{I}}=1.4 \times 10^{8}, \mathrm{Pr}=6, \mathrm{Sc}=1000$ and $\mathrm{A}=3$.

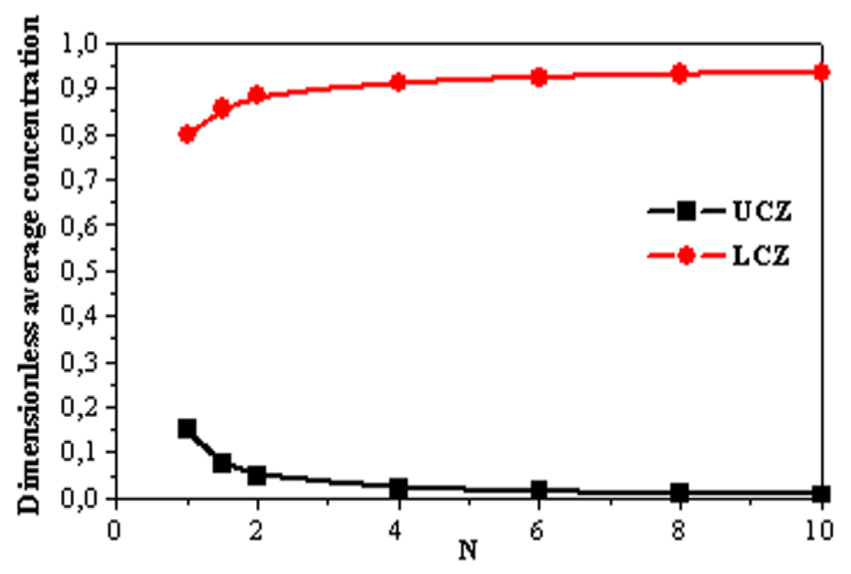




\subsection{Effect of UCZ Thickness on the Thermal Behavior of a Solar Pond}

The thermal efficiency of the pond depends on the UCZ thickness. To limit the effects of the wind on the thermal performance of the solar pond, it is important to increase the thickness of the UCZ. However, an increasing of the thickness of the UCZ reduces the amount of solar energy reaching the storage zone. Therefore, the thickness of the UCZ should be optimised.

To understand the effect of UCZ thickness on the thermal behavior of the solar pond during the absorption of solar radiation, we have reproduced in Figures 10 and 11 the temperature distribution and the development of average temperature profile in a salt-gradient solar pond at the time $\tau=0.05$ and for various thicknesses of the UCZ. The dimensionless thickness of NCZ is fixed to 0.4.

Figure 10. Evolution of temperature field with the thickness of UCZ (a-c) in a salt-gradient solar pond at $\tau=0.05$ and for $\mathrm{Ra}_{\mathrm{T}}=10^{7}, \mathrm{Ra}_{\mathrm{I}}=1.4 \times 10^{8}, \mathrm{Pr}=6, \mathrm{Sc}=1000, \mathrm{~N}=10$ and $\mathrm{A}=3$.

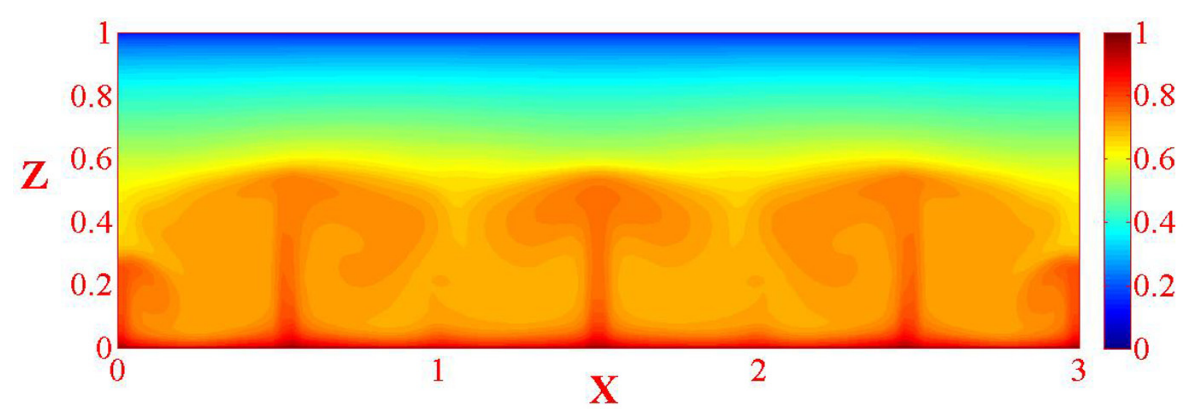

(a) $\mathrm{E}_{\mathrm{UCZ}}=0.1$

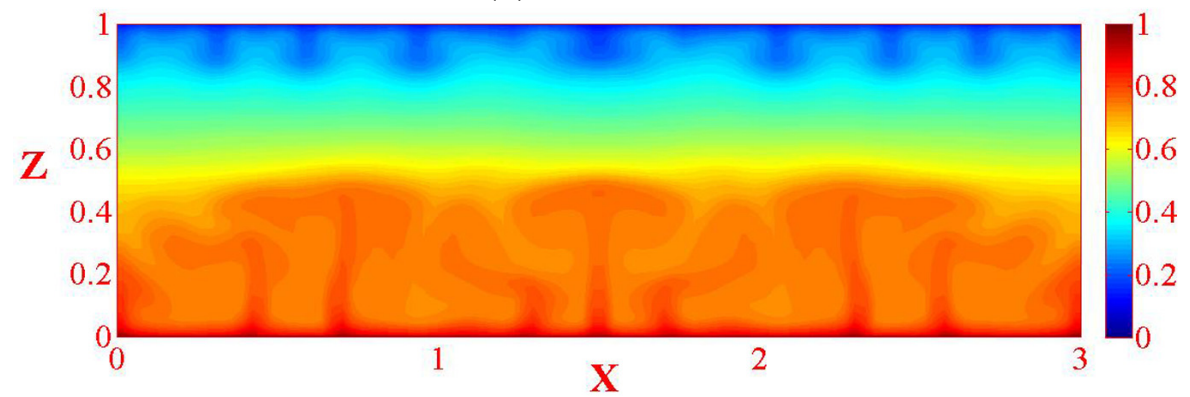

(b) $\mathrm{E}_{\mathrm{UCZ}}=0.15$

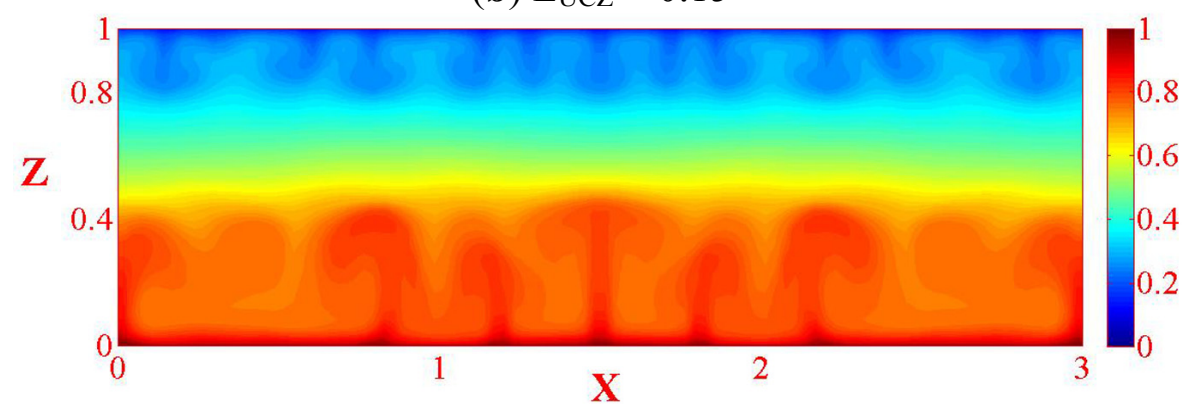

(c) $\mathrm{E}_{\mathrm{UCZ}}=0.2$ 
By comparing temperature fields illustrated in Figure $10\left(\mathrm{Ra}_{\mathrm{T}}=10^{7}\right.$ and $\left.\mathrm{N}=10\right)$, we show in the case of an intermediate value of UCZ thickness equal to 0.15 , thin convective cells appear in the UCZ. These thermal cells contribute to the homogenisation of the UCZ, which results in the protection of the solar pond. For a thickness equal to 0.2, multi-cellular thermal structures are more developed. However, for a thickness equal to 0.1 , the heat transfer in the UCZ is dominated by a conduction mechanism.

In the vicinity of the free-surface of the pond, Figure 11 shows that there is a slight increase in the temperature profile with decreasing of the temperature of $\mathrm{NCZ}$ due to the increase of the thickness of UCZ which reduces the solar radiation transmitted to the NCZ.

Figure 11. Effect of the thickness of $U C Z$ on the average temperature profile in a salt-gradient solar pond at $\tau=0.05$ and for $\mathrm{Ra}_{\mathrm{T}}=10^{7}, \mathrm{Ra}_{\mathrm{I}}=1.410^{8}, \mathrm{Pr}=6, \mathrm{Sc}=1000, \mathrm{~N}=10$ and $\mathrm{A}=3$.

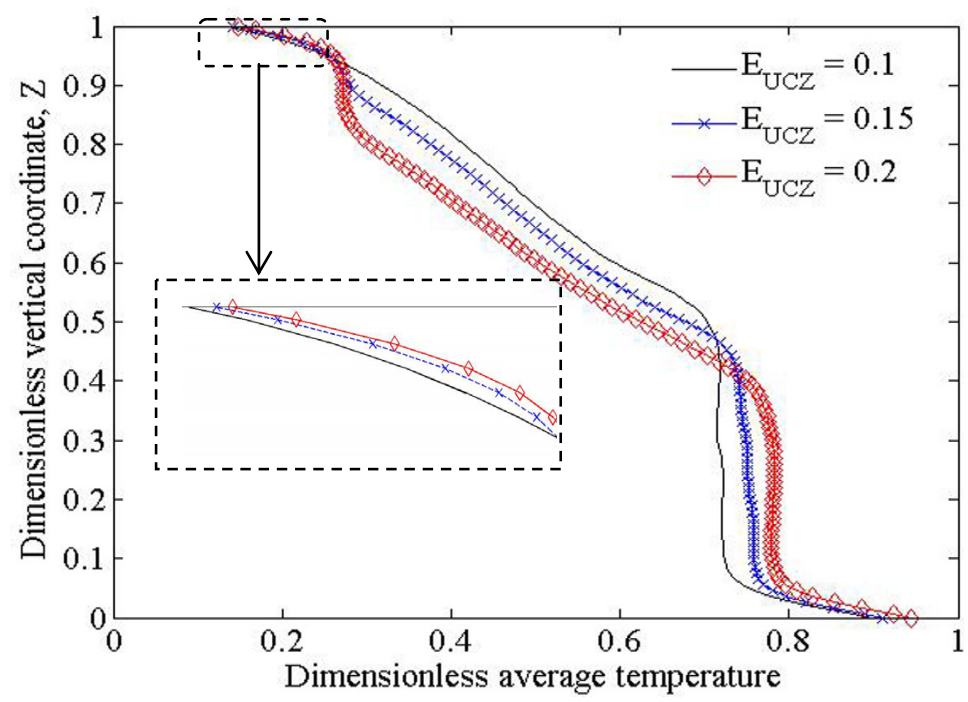

\subsection{Effects of NCZ and LCZ Thicknesses on the Thermal Behavior of a Solar Pond}

The NCZ of the solar pond can act as a thermal insulator and the LCZ is the region where the thermal energy is stored. To better understand the effects of the thicknesses of NCZ and LCZ on the thermal behavior of the solar pond during the storage of solar energy as thermal energy in the bottom of the pond, we have reproduced in Figures 12 and 13 the temperature distribution and the development of the average temperature profile in a salt-gradient solar pond at the solar heating time $\tau=0.05$ and for different thicknesses of NCZ and LCZ. The dimensionless thickness of UCZ is fixed to 0.2.

Figure 12 shows that there is a decrease of the temperature of the NCZ due to the increase of its thickness which increases the insulation property and subsequently reduces the upwards heat losses. In addition, the decrease of the thickness of LCZ will increase the temperature in this zone, as shown by Figure 13. 
Figure 12. Evolution of temperature field with the thicknesses of NCZ and LCZ (a-c) in a salt-gradient solar pond at $\tau=0.05$ and for $\mathrm{Ra}_{\mathrm{T}}=10^{7}, \mathrm{Ra}_{\mathrm{I}}=1.4 \times 10^{8}, \mathrm{Pr}=6, \mathrm{Sc}=1000$, $\mathrm{N}=10$ and $\mathrm{A}=3$.

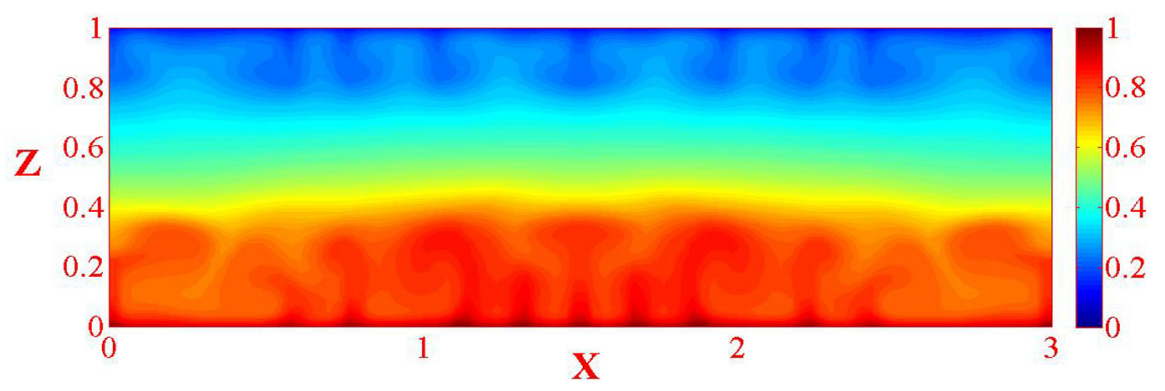

(a) $\mathrm{E}_{\mathrm{NCZ}}=0.5$ and $\mathrm{E}_{\mathrm{LCZ}}=0.3$

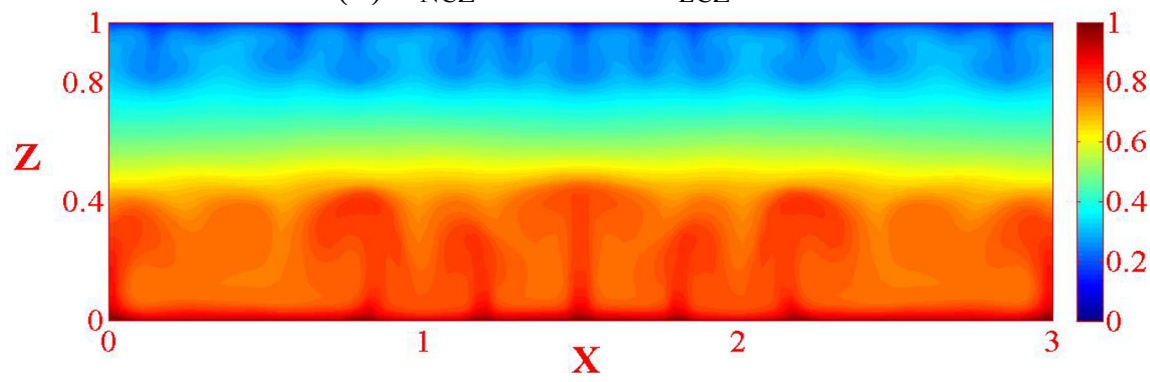

(b) $\mathrm{E}_{\mathrm{NCZ}}=0.4$ and $\mathrm{E}_{\mathrm{LCZ}}=0.4$

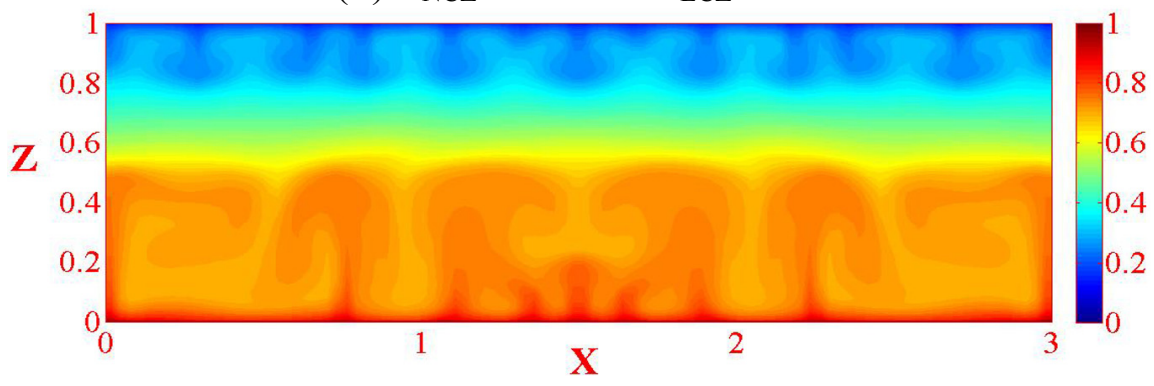

(c) $\mathrm{E}_{\mathrm{NCZ}}=0.3$ and $\mathrm{E}_{\mathrm{LCZ}}=0.5$

Figure 13. Effect of the thicknesses of $\mathrm{NCZ}$ and $\mathrm{LCZ}$ on the average temperature profile in a salt-gradient solar pond at $\tau=0.05$ and for $\mathrm{Ra}_{\mathrm{T}}=10^{7}, \mathrm{Ra}_{\mathrm{I}}=1.4 \times 10^{8}, \mathrm{Pr}=6, \mathrm{Sc}=1000$, $\mathrm{N}=10$ and $\mathrm{A}=3$.

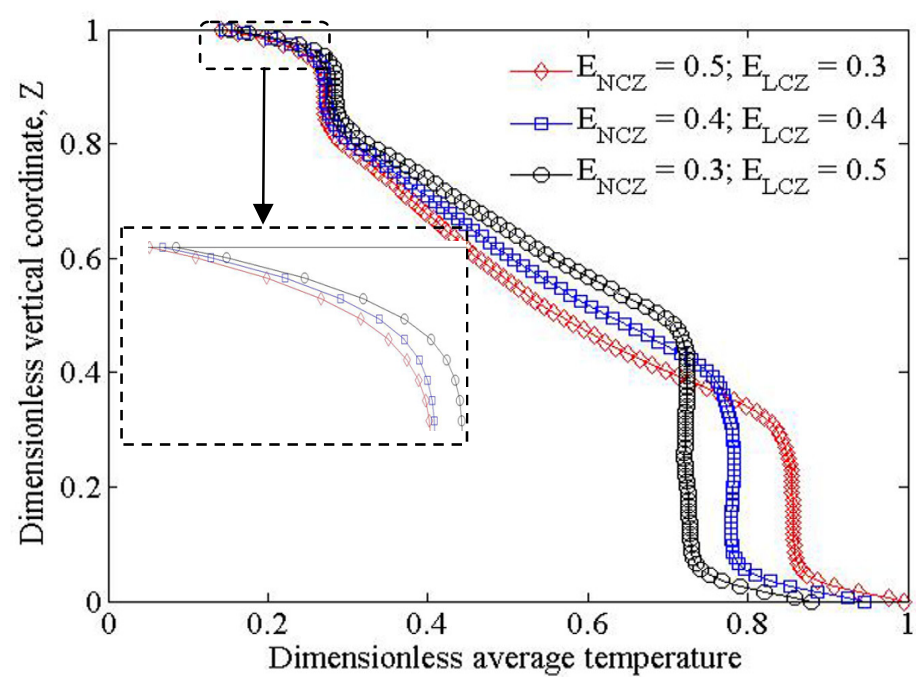




\section{Conclusions}

We have numerically studied the problem of hydrodynamic, heat and mass transfer and stability in a two-dimensional salt-gradient solar pond. The buoyancy ratio has a very important effect to prevent convection motions induced by solar radiation absorption and to stabilize the layers of salty water in the solar pond. The increase of buoyancy ratio will decrease the temperature in the upper convective zone and will preserve a high temperature in the lower convective zone. In this case, solar energy is stored as thermal energy in the lower region of the salt-gradient solar pond.

The solar heating effect is considerably higher in the lower convective zone at a buoyancy ratio equal to ten. For this value, the salt concentration gradient is stable in the pond. We clearly detected the presence of two fluid recirculation zones, one situated in the upper region of the solar pond beneath the free-surface and the second observed in the lower region near the bottom surface of the pond.

We concluded that the increase of the thickness of UCZ will increase the temperature in this zone. The thickness of NCZ has a very important effect in the reduction of the upwards heat losses which causes in this case, a rise in the temperature of LCZ.

\section{Appendix}

\section{Boundary Conditions for Heat Transfer}

A.1. The free-surface of the solar pond is subject to heat losses by convection, evaporation and radiation. These heat losses are expressed as follows: Heat losses by convection are given by Kishore and Joshi [27]; Kurt et al. [4,13]; Mansour et al. [11,12]:

$$
\mathrm{q}_{\mathrm{c}}=\mathrm{h}_{\mathrm{c}}\left(\mathrm{T}_{\mathrm{s}}-\mathrm{T}_{\mathrm{a}}\right)
$$

where $h_{c}$ represents the convective heat transfer coefficient which depends on the wind average velocit This coefficient is given by Kurt et al. [4,13]; Husain et al. [6]; Mansour et al. [11,12]:

$$
\mathrm{h}_{\mathrm{c}}=5.7+3.8 \mathrm{~V}
$$

The heat losses by evaporation are given by Kishore and Joshi [27]; Kurt et al. [4,13]; Mansour et al. [11,12]:

$$
\mathrm{q}_{\mathrm{e}}=\frac{\mathrm{L}_{\mathrm{v}} \mathrm{h}_{\mathrm{c}}\left(\mathrm{P}_{\mathrm{s}}-\mathrm{P}_{\mathrm{v}}\right)}{1.6 \mathrm{C}_{\mathrm{pa}} \mathrm{P}_{\mathrm{atm}}}
$$

$\mathrm{P}_{\mathrm{s}}$ is the vapour pressure of water at temperature $\mathrm{T}_{\mathrm{s}}$ :

$$
\mathrm{P}_{\mathrm{s}}=\exp \left(18.403-\frac{3885}{\mathrm{~T}_{\mathrm{s}}+230}\right)
$$

and $\mathrm{P}_{\mathrm{v}}$ is the partial pressure of water vapour in ambient air at temperature $\mathrm{T}_{\mathrm{a}}$ :

$$
\mathrm{P}_{\mathrm{v}}=\mathrm{R}_{\mathrm{h}} \exp \left(18.403-\frac{3885}{\mathrm{~T}_{\mathrm{a}}+230}\right)
$$

The heat losses by radiation are given by Kurt et al. [13]: 


$$
\mathrm{q}_{\mathrm{r}}=\varepsilon_{\mathrm{w}} \sigma\left(\left(\mathrm{T}_{\mathrm{s}}+273.15\right)^{4}-\left(\mathrm{T}_{\mathrm{sky}}+273.15\right)^{4}\right)
$$

and $\mathrm{T}_{\text {sky }}$ is the temperature of the sky given as follows:

$$
\mathrm{T}_{\text {sky }}=\mathrm{T}_{\mathrm{a}}+\left[0.55+0.704 \sqrt{\mathrm{P}_{\mathrm{v}}}\right]^{0.25}
$$

A.2. We assume that the quantity of solar radiation reaching the bottom of the solar pond is entirely absorbed by the fluid at this depth. If it is assumed that the bottom is thermally insulated, then the heat flux at the bottom of the solar pond is equal to the solar radiation that reaches this depth.

\section{References}

1. Kaushika, N.D.; Bansal, P.K.; Sodha, M.S. Partitioned solar pond collector/storage system. Appl. Energy 1980, 7, 169-190.

2. Bansal, P.K.; Kaushika, N.D. Salt gradient stabilized solar pond collector. Energy Convers. Manag. 1981, 21, 81-95.

3. Giestas, M.; Pina, H.; Joyce, A. The influence of radiation absorption on solar pond stability. Int. J. Heat Mass Trans. 1996, 39, 3873-3885.

4. Kurt, H.; Halici, F.; Binark, A.K. Solar pond conception-experimental and theoretical studies. Energy Convers. Manag. 2000, 41, 939-951.

5. Hassairi, M.; Safi, M.J.; Chibani, S. Natural brine solar pond: An experimental. Sol. Energy 2001, 70, 45-50.

6. Husain, M.; Patil, P.S.; Patil, S.R.; Samdarshi, S.K. Computer simulation of salt gradient solar pond's thermal behaviour. Renew. Energy 2003, 28, 769-802.

7. Husain, M.; Patil, P.S.; Patil, S.R.; Samdarshi, S.K. Simple methods for estimation of radiation flux in solar ponds. Energy Convers. Manag. 2004, 45, 303-314.

8. Hull, J.R. Calculation of solar pond thermal efficiency with diffusively reflecting bottom. Sol. Energy 1982, 29, 385-389.

9. Angeli, C.; Leonardi, E. A one-dimensional study of the salt diffusion in a salinity gradient solar pond. Int. J. Heat Mass Trans. 2004, 47, 1-10.

10. Jaefarzadeh, M.R. Thermal behavior of a small salinity-gradient solar pond with wall shading effect. Sol. Energy 2004, 77, 281-290.

11. Mansour, R.B.; Nguyen, C.T.; Galanis, N. Numerical study of transient heat and mass transfer and stability in a salt-gradient solar pond. Int. J. Therm. Sci. 2004, 43, 779-790.

12. Mansour, R.B.; Nguyen, C.T.; Galanis, N. Transient heat and mass transfer and long-term stability of salt-gradient solar pond. Mech. Res. Commun. 2006, 33, 233-249.

13. Kurt, H.; Ozkaymak, M.; Binark, A.K. Experimental and numerical analysis of sodium-carbonate salt-gradient solar pond performance under simulated solar radiation. Appl. Energy 2006, 83, 324-342.

14. Karakilcik, M.; Dincer, I.; Rosen, M.A. Performance investigation of a solar pond. Appl. Therm. Eng. 2006, 26, 727-735.

15. Hammami, M.; Mseddi, M.; Baccar, M. Transient natural convection in an enclosure with vertical solutal gradients. Sol. Energy 2007, 81, 476-487. 
16. Ould Dah, M.M.; Ouni, M.; Guizani, A.; Belghith, A. The influence of the heat extraction mode on the performance and stability of a mini solar pond. Appl. Energy 2010, 87, 3005-3010.

17. Suarez, F.; Tyler, S.W.; Childress, A.E. A fully coupled, transient double-diffusive convective model for salt-gradient solar ponds. Int. J. Heat Mass Trans. 2010, 53, 1718-1730.

18. Wang, H.; Xie, M.; Sun, W. Nonlinear dynamic behavior of non-convective zone in salt gradient solar pond. Sol. Energy 2011, 85, 1745-1757.

19. Rabl, A.; Nielson, C.E. Solar ponds for space heating. Sol. Energy 1975, 17, 1-12.

20. Wang, Y.F.; Akbarzadeh, A.A. A parametric study on solar ponds. Sol. Energy 1983, 30, 555-562.

21. Beniwal, R.S.; Singh, R. Calculation of thermal efficiency of salt-gradient solar ponds. Heat Recover. Syst. CHP 1987, 7, 497-516.

22. Defant, A. Physical Oceanography; Pergamon Press: Oxford, UK, 1961; Volume 1, p. 53.

23. Patankar, S.V. Numerical Heat Transfer and Fluid Flow; Hemisphere Publishing Corporation: Washington, DC, USA, 1980.

24. Baccar, M. Modélisation Numérique Tridimensionnelle des Comportements Hydrodynamique et Thermique en Cuve Agitée [in French]. Ph.D. Dissertation, Polytechnique Institute of Toulouse, Toulouse, France, 1990.

25. Peaceman, D.W.; Rachford, H.H. The numerical solution of parabolic and elliptic differential equations. J. Soc. Ind. Appl. Math. 1955, 3, 28-41.

26. Han, H.; Kuehn, T.H. Double-diffusive natural convection in a vertical rectangular enclosure-II. Numerical study. Int. J. Heat Mass Trans. 1991, 34, 461-471.

27. Kishore, V.V.N.; Joshi, V. A practical collector efficiency equation for non-convecting solar ponds. Sol. Energy 1984, 33, 391-395.

(C) 2012 by the authors; licensee MDPI, Basel, Switzerland. This article is an open access article distributed under the terms and conditions of the Creative Commons Attribution license (http://creativecommons.org/licenses/by/3.0/). 